\title{
Prediction equations for the estimation of body composition in the elderly using anthropometric data
}

\author{
BY MARJOLEIN VISSER*, ELLEN VAN DEN HEUVEL \\ AND PAUL DEURENBERG \\ Department of Human Nutrition, Wageningen Agricultural University, PO Box 8129, \\ $6700 \mathrm{EV}$ Wageningen, The Netherlands
}

(Received 20 May 1993 - Revised 6 September 1993-Accepted 14 September 1993)

\begin{abstract}
To study the relationship between health and nutritional status in elderly populations, information about body composition is essential. To collect this information in large epidemiological studies, practical methods based on anthropometric data must be available. In the present study the relationship between body composition, determined by densitometry, and anthropometric data in 204 elderly men and women, aged 60-87 years, was analysed. Existing prediction equations described in the literature, and mainly based on young and middle-aged subjects, generally underestimated percentage body fat in the elderly study population. Therefore, new prediction equations were developed, based on sex and the sum of two (biceps and triceps) or four (biceps, triceps, suprailiaca and subscapula) skinfolds or the body mass index (BMI). Addition of age or body circumferences to the models did not improve the prediction of body density. Internal cross validation and external validation revealed that the formulas are valid for the estimation of body density in elderly subjects. The standard errors of estimate of the three models, expressed as percentage body fat, were $5.6,5.4$ and $4.8 \%$ respectively.
\end{abstract}

Body composition: Anthropometric measurement: Elderly

The number of elderly people is increasing in industrialized countries as well as in developing countries. Information about health status, and especially factors influencing health in old age, is therefore needed. Various studies have shown a relationship between health and nutritional status in the elderly. While studying this relationship, information concerning body composition is indispensable (Chumlea \& Baumgartner, 1989; Kuczmarski, 1989). Body-fat content and distribution in elderly subjects seem to be related to risk factors for cardiovascular disease such as high blood pressure (Löwik et al. 1991; Kubena et al. 1991), lower plasma high-density-lipoprotein (HDL)-cholesterol and higher plasma triacylglycerol concentrations (Chumlea et al. 1992) and diabetes (Kaye et al. 1991; Kubena et al. 1991). Underweight and undernutrition in old age are found to be related to higher mortality rates (Mattila et al. 1986; Volkert et al. 1992).

To study the effect of body composition on morbidity and mortality, large epidemiological studies are requisite. However, commonly used methods for the assessment of body composition such as densitometry are difficult to perform in elderly subjects and are not suitable for field studies. Apart from that, the densitometric method also has its limitations in elderly subjects as the assumptions underlying this method, i.e. a density of the fat mass of $0.900 \mathrm{~kg} / 1$ and a density of the fat-free mass of $1.100 \mathrm{~kg} / 1$, may be incorrect for elderly subjects (Deurenberg et al. $1989 \mathrm{~b}$ ). Body composition predicted from relatively simple anthropometric measures is more practical. 
Various prediction formulas for content of body fat based on skinfolds (Durnin \& Womersley, 1974; Noppa et al. 1979; Heitman, 1990), body mass index (BMI) (Womersley \& Durnin, 1977; Norgan \& Ferro-Luzzi, 1982; Garrow \& Webster, 1985; Heitman, 1990; Deurenberg et al. 1991) or both (Svendsen et al. 1991) have been described in the literature. However, these formulas were mostly developed in young and middle-aged populations (Norgan \& Ferro-Luzzi, 1982; Garrow \& Webster, 1985; Heitman, 1990; Deurenberg et al. 1991); or rather small groups of elderly (Durnin \& Womersley, 1974; Womersley \& Durnin, 1977; Noppa et al. 1979; Svendsen et al. 1991).

Both cross-sectional and longitudinal studies show that body composition changes with age. The amount of fat in the body generally increases and relatively more fat is accumulated internally (Borkan \& Norris, 1977; Schwartz et al. 1990; Carmelli et al. 1991). Stature decreases with increasing age due to senile kyphosis and shortening of the spinal vertebrae (Kucsmarski, 1989). Therefore, prediction formulas developed in young and middle-aged subjects based on skinfolds, weight, height or the BMI, are not likely to be valid in elderly subjects.

The aim of the present study was to investigate the relationship between body density and anthropometric measurements in a large group of elderly men and women, aged 60 to 87 years of age.

\section{SUBJECTS AND METHODS}

\section{Subjects}

The study population was composed of 204 apparently healthy elderly subjects, 128 women and seventy-six men, aged $60-87$ years. The subjects were recruited by advertisements in local newspapers and by visiting homes and clubs for the elderly in the surroundings of Wageningen. All subjects completed a medical questionnaire which was checked by a physician. Subjects taking diuretic drugs that could influence body composition or the state of hydration, and heavy smokers ( $>10$ cigarettes/d) were excluded from the study. The experimental procedures were approved by the Ethical Committee of the Department of Human Nutrition. Characteristics of the subjects are given in Table 1. For external validation the data of twenty-three elderly people, aged 62-82 years, were used. These subjects were measured at the Department of Human Biology, University of Limburg, using the same methodology.

\section{Body composition}

Anthropometric measurements and the measurement of body density were performed on the same day. Body weight was measured to the nearest $0.05 \mathrm{~kg}$ using a digital scale (ED60-T; Berkel, Rotterdam, The Netherlands). Body height was measured by means of a microtoise to the nearest $0.001 \mathrm{~m}$. BMI was calculated as body weight $(\mathrm{kg})$ divided by height $(\mathrm{m})$ squared.

Body density was determined by underwater weighing to the nearest $0.001 \mathrm{~kg}$ (3826MP 81; Sartorius, Göttingen, Germany) with simultaneous determination of the lung volume by a helium dilution technique (Spiro-Junior; Jaeger GmBH, Würtzburg, Germany). The measurement was carried out in duplicate if possible. Body fat content (\%) was calculated from density using Siri's formula (Siri, 1961).

\section{Skinfolds}

Skinfolds were measured at the left side of the body to the nearest $0.002 \mathrm{~m}$ with Harpenden skinfold callipers (Holtain Ltd, Bryberian, Crymmych). The skinfolds were measured in triplicate at the following sites: (1) triceps, halfway between the acromion process and the olecranon process; (2) biceps, at the same level as the triceps skinfold, directly above the 
Table 1. Subject characteristics

\begin{tabular}{|c|c|c|c|c|}
\hline & \multicolumn{2}{|c|}{ Women $(n 128)$} & \multicolumn{2}{|c|}{ Men $(n 76)$} \\
\hline & Mean & SD & Mean & SD \\
\hline Age (years) & $70 \cdot 2$ & $5 \cdot 3$ & $71 \cdot 0$ & $5 \cdot 9$ \\
\hline Body weight $(\mathrm{kg})$ & $68 \cdot 1$ & $9 \cdot 5$ & $76 \cdot 5^{* * *}$ & $9 \cdot 6$ \\
\hline Body height (m) & 1.616 & 0.061 & $1 \cdot 752 * * *$ & 0.071 \\
\hline Body mass index $\left(\mathrm{kg} / \mathrm{m}^{2}\right)$ & $26 \cdot 1$ & $3 \cdot 6$ & $24 \cdot 9^{* *}$ & $2 \cdot 6$ \\
\hline Density $(\mathrm{kg} / \mathrm{l})$ & 1.0037 & 0.0124 & $1 \cdot 0289 * * *$ & 0.0119 \\
\hline Body fat content $(\%) \dagger$ & $43 \cdot 3$ & $6 \cdot 1$ & $31 \cdot 2 * * *$ & $5 \cdot 6$ \\
\hline Triceps (mm) & $19 \cdot 8$ & $5 \cdot 1$ & $12 \cdot 5^{* * *}$ & $3 \cdot 3$ \\
\hline Biceps (mm) & 11.8 & $4 \cdot 5$ & $6 \cdot 4^{* * *}$ & $2 \cdot 2$ \\
\hline Subscapula (mm) & 19.8 & $7 \cdot 5$ & $17 \cdot 4^{* *}$ & $5 \cdot 5$ \\
\hline Suprailiaca (mm) & $19 \cdot 8$ & $8 \cdot 0$ & $17 \cdot 9$ & 62 \\
\hline Para-umbilica (mm) $\ddagger$ & $25 \cdot 7$ & $7 \cdot 7$ & $20 \cdot 7 * * *$ & $6 \cdot 2$ \\
\hline Quadriceps $(\mathrm{mm}) \S$ & $32 \cdot 5$ & $7 \cdot 1$ & $16 \cdot 5^{* * *}$ & 6.6 \\
\hline Fibula $(\mathrm{mm})$ & $15 \cdot 3$ & 60 & $7 \cdot 4 * * *$ & 2.8 \\
\hline
\end{tabular}

Significantly different from women; ${ }^{* *} P<0.01,{ }^{* * *} P<0 \cdot 001$.

$\dagger$ Calculated using Siri's formula.

$\$ 125$ women, seventy men.

\$ Sixty-two women, thirty-nine men.

Fifty-nine women, thirty-three men.

centre of the cubital fossa; (3) sub-scapula, about $20 \mathrm{~mm}$ below the tip of the scapula, at an angle of $45^{\circ}$ to the lateral side of the body; (4) suprailiaca, just above the ilia crest, in the axillary line; (5) para-umbilica, at one-third of the distance between the umbilicus and the lateral side of the body; (6) quadriceps, halfway between the ilia crest and the patella in a vertical line; (7) fibula, on the fibula at the level of the greatest circumference. The paraumbilica, quadriceps and fibula were only measured in a subgroup of the population. The average value of the triplicate measurements was used in the statistical analysis. All skinfolds, and the sums of skinfolds, were $\log _{10}$ transformed to correct for a skewed distribution.

\section{Statistical methods}

Correlations between body density and other body composition variables were calculated using Pearson's product-moment correlations. Differences between density from underwater weighing and density predicted from skinfolds or BMI equations were tested with paired Student's $t$ tests. Stepwise multiple regression analysis was used with density as the dependent variable and sex, age, BMI or (sums of) skinfolds as independent variables. Prediction equations were developed in two groups (randomly assigned by a computer program) of the total population. Internal cross validation was carried out by testing whether the prediction equation of one group could validly predict density in the other group. The prediction equation based on the total study population was applied to body composition data from another group of Dutch elderly subjects to validate the equation externally. Two-sided $P$ values were considered statistically significant at $P<0.05$. Results are expressed as means with their standard deviations (SD).

\section{RESULTS}

Table 1 shows some characteristics of the subjects. All variables, except age and the suprailiaca skinfold, were statistically different between the sexes. Men were taller and had 
Table 2. Differences between body fat content $(\%)$ predicted from various equations in the literature and estimated by densitometry using Siri's (1961) formula (difference = predicted-estimated)

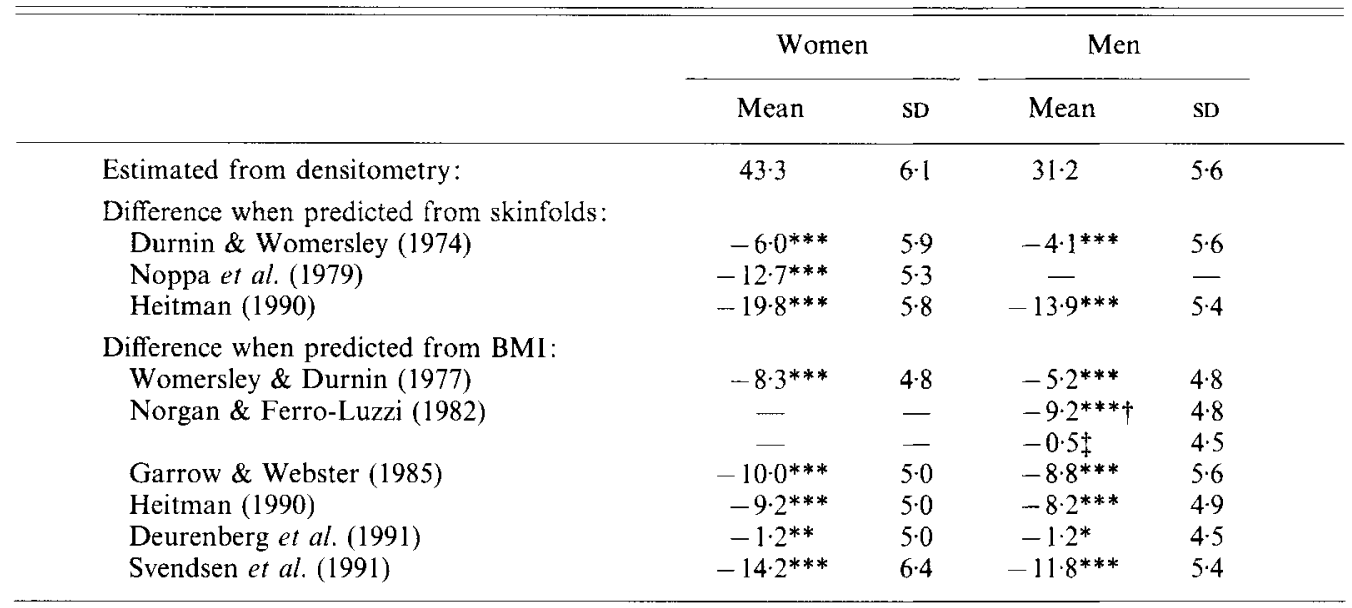

Mean predicted value was significantly different from the estimated value : $P<0.05,{ }^{* *} P<0 \cdot 01,{ }^{* * *} P<0 \cdot 001$.

$\uparrow$ Equation included BMI only.

\$ Equation included BMI and age.

a higher body weight compared with the women. The body density of the women was lower, resulting in a higher proportion of body fat. Nearly all skinfold thicknesses were larger and BMI was higher in women.

To investigate whether prediction formulas from the literature were able to predict body fat content in this group of elderly subjects, various formulas were applied to the data (Table 2). Nearly all formulas significantly underestimated the percentage body fat in this population. Prediction errors of body fat percentage ranged from $-19.8 \%$ to $-1.2 \%$ in women and from $-13.9 \%$ to $-0.5 \%$ in men.

Because of the large mean differences between predicted and measured body fat contents, new prediction formulas were developed using skinfolds, BMI, sex and age as independent variables.

In Table 3 the correlation coefficients between body density and several skinfolds and BMI are shown. In women all skinfolds were significantly correlated with body density. In men no correlation was found between body density and the para-umbilica skinfold, the quadriceps skinfold and the fibula skinfold. Generally, both in men and women, the skinfolds on the trunk were more highly correlated with body density than the skinfolds on the extremities, except for the umbilica skinfold in men. The correlation of body density and BMI was higher than any correlation of the body density with skinfolds, in both males and females.

After the total study population was randomly assigned into two groups, prediction equations for body density were developed in each subgroup using multi-linear regression techniques. Group 1 consisted of 109 subjects, seventy-four women and thirty-five men, while group 2 consisted of ninety-five subjects, fifty-four women and forty-one men. The results of three models in each group are shown in Table 4 . The regression model with the highest explained variance $\left(R^{2}\right)$ and the lowest prediction error (standard error of estimate, SEE) in both subgroups contained gender and BMI as independent variables. The best 
Table 3. Pearson's product-moment correlation coefficients between body density and (the sum of) skinfolds $(\mathrm{mm})$ or the body mass index $\left(\mathrm{kg} / \mathrm{m}^{2}\right)$ in elderly men and women

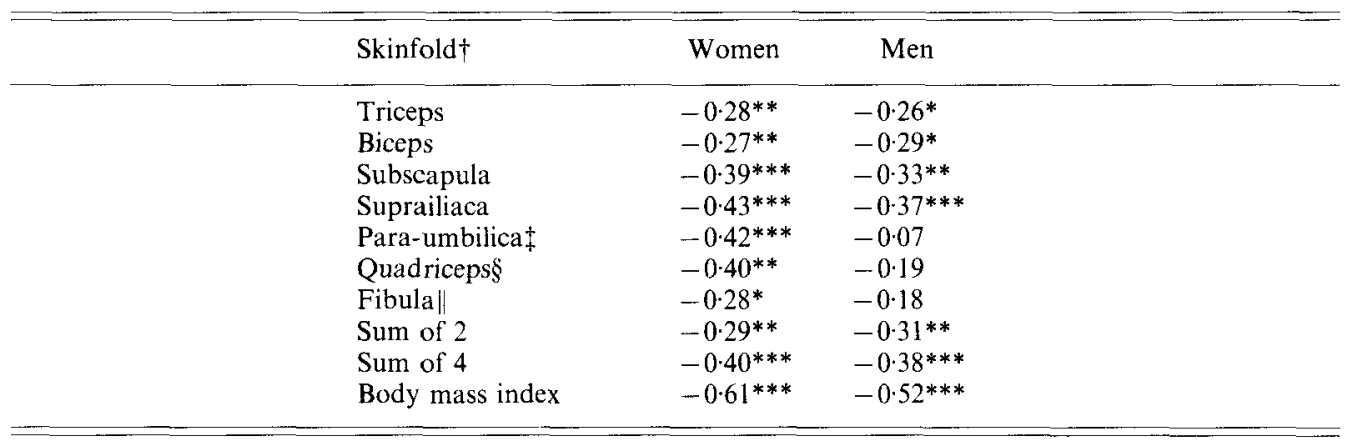

* $P<0.05,{ }^{* *} P<0.01,{ }^{* * *} P<0.001$.

$\dagger$ Skinfolds were $\log _{10}$ transformed; sum of $2=\log _{10}$ (biceps + triceps); sum of $4=\log _{10}$ (biceps + triceps + subscapula + suprailiaca).

+ Values from 125 women and seventy men.

$\S$ Values from sixty-two women and thirty-nine men.

i| Values from fifty-nine women and thirty-three men.

Table 4. Multiple linear regression of body density against sex, skinfold thickness and body mass index in the two random groups and in the total population

(Regression coefficients with their standard errors)

\begin{tabular}{|c|c|c|c|c|c|c|}
\hline & \multicolumn{2}{|c|}{ Group $1(n$ 109) } & \multicolumn{2}{|c|}{ Group $2(n 95)$} & \multicolumn{2}{|c|}{ Total (n 204) } \\
\hline & Coeff & $\mathrm{SE}$ & Coeff & $\mathrm{SE}$ & Coeff & SE \\
\hline \multicolumn{7}{|l|}{ Model 1} \\
\hline Sext & $0 \cdot 0183^{*}$ & 0.0033 & $0 \cdot 0189$ & 0.0031 & $0 \cdot 0186$ & $0 \cdot 0023$ \\
\hline $\log _{10}(\text { sum of } 2)_{\ddagger}^{\ddagger}$ & -0.0359 & 0.0103 & -0.0248 & 0.0092 & -0.0300 & 0.0069 \\
\hline Intercept & $1 \cdot 0567$ & 0.0151 & 1.0406 & 0.0137 & $1 \cdot 0481$ & 0.0102 \\
\hline$R^{2}$ & \multicolumn{2}{|c|}{0.54} & \multicolumn{2}{|c|}{0.56} & \multicolumn{2}{|c|}{0.55} \\
\hline $\mathrm{SEE}$ & \multicolumn{2}{|c|}{0.0121} & \multicolumn{2}{|c|}{0.0114} & \multicolumn{2}{|c|}{0.0117} \\
\hline \multicolumn{7}{|l|}{ Model 2} \\
\hline $\operatorname{Sex} x^{\dagger}$ & $0 \cdot 0213$ & 0.0025 & 0.0213 & 0.0025 & $0 \cdot 0212$ & $0 \cdot 0018$ \\
\hline $\log _{10}($ sum of 4$) \ddagger$ & $-0 \cdot 0440$ & 0.0087 & -0.0281 & 0.0080 & -0.0356 & 0.0059 \\
\hline Intercept & 1.0842 & 0.0160 & 1.0551 & 0.0149 & 1.0688 & 0.0109 \\
\hline$R^{2}$ & \multirow{2}{*}{\multicolumn{2}{|c|}{$\begin{array}{l}0.58 \\
0.0115\end{array}$}} & \multirow{2}{*}{\multicolumn{2}{|c|}{$\begin{array}{l}0.58 \\
0.0111\end{array}$}} & \multicolumn{2}{|c|}{0.58} \\
\hline SEE & & & & & & \\
\hline \multicolumn{7}{|l|}{ Model 3} \\
\hline Sex & $0-0223$ & 0.0021 & $0 \cdot 0226$ & 0.0021 & 0.0226 & 0.0015 \\
\hline Body mass index & -0.0026 & 0.0003 & -0.0018 & 0.0003 & -0.0022 & 0.0002 \\
\hline Intercept & 1.0704 & 0.0084 & 1.0517 & 0.0079 & 1.0605 & 0.0057 \\
\hline$R^{2}$ & \multicolumn{2}{|c|}{0.68} & \multicolumn{2}{|c|}{0.66} & \multicolumn{2}{|c|}{0.67} \\
\hline SEE & \multicolumn{2}{|c|}{0.0101} & \multicolumn{2}{|c|}{0.0099} & \multicolumn{2}{|c|}{$0 \cdot 0100$} \\
\hline
\end{tabular}

$R^{2}$, explained variance; SEE, standard error of estimate.

* All independent variables contribute significantly to the models $(P<0.01)$.

$\dagger$ Sex, 0 for women, 1 for men.

$\ddagger$ Sum of 2, biceps + triceps $(\mathrm{mm})$; sum of 4 , biceps + triceps + subscapula + suprailiaca $(\mathrm{mm})$. 
Table 5. Internal cross validation of the three equations developed for the prediction of body density and body fat content in the two random groups (difference $=$ measured-predicted)

(Mean values and standard deviations)

\begin{tabular}{|c|c|c|c|c|}
\hline \multirow[b]{2}{*}{ Method used } & \multicolumn{2}{|c|}{ Group 1 (n 109) } & \multicolumn{2}{|c|}{ Group $2(n 95)$} \\
\hline & Mean & SD & Mean & SD \\
\hline $\begin{array}{l}\text { Density }(\mathrm{kg} / \mathrm{l}) \\
\text { Densitometry }\end{array}$ & 1.0120 & 0.0176 & 1.0143 & 0.0169 \\
\hline $\begin{array}{l}\text { Predicted using model } 1 \\
\text { Difference }\end{array}$ & $\begin{array}{l}1.0117 \\
0.0003\end{array}$ & $\begin{array}{l}0.0117 \\
0.0121\end{array}$ & $\begin{array}{r}1.0147 \\
-0.0005\end{array}$ & $\begin{array}{l}0.0139 \\
0.0114\end{array}$ \\
\hline $\begin{array}{l}\text { Predicted using model } 2 \\
\text { Difference }\end{array}$ & $\begin{array}{l}1.0114 \\
0.0006\end{array}$ & $\begin{array}{l}0.0120 \\
0.0115\end{array}$ & $\begin{array}{r}1.0152 \\
-0.0009\end{array}$ & $\begin{array}{l}0.0145 \\
0.0113\end{array}$ \\
\hline $\begin{array}{l}\text { Predicted using model } 3 \\
\text { Difference }\end{array}$ & $\begin{array}{r}1.0122 \\
-0.0002\end{array}$ & $\begin{array}{l}0.0131 \\
0.0102\end{array}$ & $\begin{array}{l}1 \cdot 0139 \\
0.0004\end{array}$ & $\begin{array}{l}0.0153 \\
0.0102\end{array}$ \\
\hline $\begin{array}{l}\text { Body fat content ( } \% \text { ) } \\
\text { Densitometry }\end{array}$ & $39 \cdot 27$ & $8 \cdot 47$ & $38 \cdot 17$ & 8.09 \\
\hline $\begin{array}{l}\text { Predicted using model } 1 \\
\text { Difference }\end{array}$ & $\begin{array}{r}39 \cdot 28 \\
-0.01\end{array}$ & $\begin{array}{l}5 \cdot 87 \\
5 \cdot 80\end{array}$ & $\begin{array}{r}38.03 \\
0.14\end{array}$ & $\begin{array}{r}6 \cdot 33 \\
5 \cdot 42\end{array}$ \\
\hline $\begin{array}{l}\text { Predicted using model } 2 \\
\text { Difference }\end{array}$ & $\begin{array}{r}39 \cdot 37 \\
-0 \cdot 10\end{array}$ & $\begin{array}{l}6.05 \\
5.51\end{array}$ & $\begin{array}{r}37.94 \\
0.23\end{array}$ & $\begin{array}{l}6 \cdot 50 \\
5 \cdot 32\end{array}$ \\
\hline $\begin{array}{l}\text { Predicted using model } 3 \\
\text { Difference }\end{array}$ & $\begin{array}{r}39 \cdot 17 \\
0 \cdot 11\end{array}$ & $\begin{array}{l}6 \cdot 61 \\
4.84\end{array}$ & $\begin{array}{r}38 \cdot 20 \\
-0.03\end{array}$ & $\begin{array}{l}6 \cdot 97 \\
4 \cdot 76\end{array}$ \\
\hline
\end{tabular}

regression model using skinfolds contained the variables sex and the $\log _{10}$ transformed sum of biceps, triceps, subscapula and suprailiaca. However, a model based on sex and the $\log _{10}$ transformed sum of only the triceps and biceps skinfold had only a slightly lower explained variance and a comparable prediction error. Age did not contribute to the explained variance in either subgroup.

Internal cross validation revealed that the prediction equation developed in one subgroup could validly predict body density in the other subgroup (Table 5). Therefore, the data from the groups could be combined (Table 4 ). The correlation coefficients between measured and predicted densities in group 1 and group 2 were 0.73 and 0.74 respectively using model $1,0.76$ and 0.76 respectively using model 2 , and 0.82 and 0.81 respectively using model 3 (all $P<0.0001$ ). The SEE in body density of the models varied from 0.01 to $0.0117 \mathrm{~kg} / \mathrm{l}$, resulting in a prediction error of about $5 \%$ body fat at a body density of $1 \cdot 0030 \mathrm{~kg} / \mathrm{l}$.

External validation of the developed prediction formulas was carried out using the body composition data from an independent sample of twenty-three elderly subjects. The main characteristics of this population are presented in Table 6 . The suprailiaca skinfold and the subscapula skinfold were not measured in this population. Therefore, prediction model 2 , using the sum of four skinfolds, could not be validated. Body density of these elderly subjects, predicted by model 1 and model 3, was not significantly different from the measured value (Table 6). The differences were -0.0072 and $-0.0054 \mathrm{~kg} / 1$ for the two models respectively in women, and -0.0011 and $-0.0055 \mathrm{~kg} / 1$ respectively in men. When these values were expressed as percentage body fat the differences were $+3.5(\mathrm{SD} 7 \cdot 3)$ and $+2.5($ SD 5.9$) \%$ in women, and $+0.5($ SD 5.3) and $+2.5($ SD 5.2$) \%$ in men. 
Table 6. External validation; population characteristics, the difference (difference = measured-predicted) and the Pearson's correlation coefficients between predicted and measured body density and body fat content

(Mean values and standard deviations)

\begin{tabular}{|c|c|c|c|c|}
\hline \multirow[t]{2}{*}{ Subjects... } & \multicolumn{2}{|c|}{$\begin{array}{c}\text { Women } \\
(n \text { 11) }\end{array}$} & \multicolumn{2}{|c|}{$\begin{array}{c}\text { Men } \\
(n 12)\end{array}$} \\
\hline & Mean & SD & Mean & SD \\
\hline Age (years) & $73 \cdot 3$ & $5 \cdot 7$ & $68 \cdot 8$ & $4 \cdot 3$ \\
\hline Body weight (kg) & $66 \cdot 7$ & 6.0 & $79 \cdot 8$ & $7 \cdot 2$ \\
\hline Body height (m) & $1 \cdot 561$ & 0.052 & $1 \cdot 709$ & 0.059 \\
\hline Body mass index $\left(\mathrm{kg} / \mathrm{m}^{2}\right)$ & $27 \cdot 4$ & $1 \cdot 9$ & $27 \cdot 3$ & $2 \cdot 0$ \\
\hline Sum of biceps and triceps (mm) & $44 \cdot 4$ & $11 \cdot 1$ & $20 \cdot 2$ & $5 \cdot 3$ \\
\hline \multicolumn{5}{|l|}{ Density $(\mathrm{kg} / \mathrm{l})$} \\
\hline Measured & 1.0063 & $0 \cdot 0147$ & $1 \cdot 0291$ & $0 \cdot 0120$ \\
\hline Difference using prediction model 1 & -0.0072 & $0 \cdot 0151$ & -0.0011 & 0.0114 \\
\hline Correlation coefficient & \multicolumn{2}{|c|}{0.01} & \multicolumn{2}{|c|}{0.33} \\
\hline Difference using prediction model 3 & -0.0054 & $0 \cdot 0121$ & -0.0055 & 0.0111 \\
\hline Correlation coefficient & \multicolumn{2}{|c|}{$0.71^{*}$} & \multicolumn{2}{|c|}{0.39} \\
\hline \multicolumn{5}{|l|}{ Body fat content $(\%)$} \\
\hline Measured & $42 \cdot 00$ & $7 \cdot 18$ & $31 \cdot 05$ & 5.63 \\
\hline Difference using prediction model 1 & $3 \cdot 48$ & $7 \cdot 34$ & $0 \cdot 46$ & $5 \cdot 34$ \\
\hline Correlation coefficient & \multicolumn{2}{|c|}{$0 \cdot 01$} & \multicolumn{2}{|c|}{$0 \cdot 33$} \\
\hline Difference using prediction model 3 & $2 \cdot 54$ & $5 \cdot 91$ & $2 \cdot 51$ & $5 \cdot 20$ \\
\hline Cortelation coefficient & \multicolumn{2}{|c|}{$0.71 *$} & \multicolumn{2}{|c|}{$0 \cdot 39$} \\
\hline
\end{tabular}

${ }^{*} P<0.05$

\section{DISCUSSION}

The subjects in the present study were volunteers recruited in the surroundings of Wageningen. The sample is therefore not representative of the elderly in The Netherlands. However, comparison of weight and height of the study sample with data from the Central Bureau of Statistics revealed that the study sample was not very different from the general elderly population (aged 60 years or more) in The Netherlands (males: $76.6 \mathrm{~kg}, 1.747 \mathrm{~m}$, females: $68.3 \mathrm{~kg}, 1.644 \mathrm{~m}$; Centraal Bureau voor de Statistiek, 1992). The BMI and body composition data are also comparable with data from other studies carried out on the elderly in The Netherlands (de Groot et al. 1991; Minten et al. 1991).

When prediction equations from the literature were applied to the study sample nearly all equations underestimated body fat content. The equations including age as an independent continuous variable (Norgan \& Ferro-Luzzi, 1982; Deurenberg et al. 1991) showed the most accurate prediction of percentage body fat. The other equations from the literature which were generally developed using young to middle-aged subjects largely underestimated body fat content. Of these equations the equation of Durnin \& Womersley (1974), based on skinfold thickness, showed the best result. When comparing the body fat content of the subjects in the studies of Noppa et al. (1979) and Svendsen et al. (1991), it is remarkable that they are much lower compared with those observed in the present study, the study of Durnin \& Womersley (1974) and the study of Womersley \& Durnin (1977). The BMI of the subjects of the study of Svendsen et al. (1991) is, however, comparable with the present study but body fat, determined by dual-energy X-ray absorptiometry, is much lower. These authors suggested that population specificity may have caused the large differences. It seems unlikely that differences between the Danish population and the Dutch 
population are the basis of these large differences. Differences in body fat content between populations are more likely to be caused by age differences and/or the different methods used to estimate body fat (Blanchard et al. 1990; Baumgartner et al. 1991; Johansson et al. 1993).

The skinfold thickness that was best correlated with body density in both elderly men and women was the suprailiaca. A prediction model for body density based on this single skinfold and sex had an explained variance of $59 \%$ and a SEE of $0.0112 \mathrm{~kg} / \mathrm{l}$. Despite the fact that this model was comparable with the model using sex and the sum of four skinfolds, this model was not evaluated further. A prediction formula based on only one skinfold will lead to considerable errors when the skinfold is measured inaccurately or when the subjects have an unusual subcutaneous fat distribution. Therefore, only models based on more than one skinfold were investigated. Models based on sex and the sum of skinfolds had higher explained variances and lower SEE than sex-specific models or models based on separate skinfolds (results not shown). Since there was no interaction between sex and the sum of skinfolds (or sex and BMI) in the elderly population, only one single prediction model was developed for both sexes combined, adding sex as a dummy variable. The model with sex and the sum of triceps, biceps, subscapula and suprailiaca as independent variables predicted body density in the elderly slightly better $\left(R^{2} 0.58\right.$, SEE $\left.0.0113 \mathrm{~kg} / \mathrm{l}\right)$ compared with a model using sex and the sum of the triceps and biceps skinfold $\left(R^{2} 0.55\right.$, SEE $\left.0.0117 \mathrm{~kg} / \mathrm{l}\right)$. A model based on these two skinfolds has several practical advantages. The biceps and triceps skinfolds are relatively easy to measure, even when the elderly subject is confined to a wheelchair or is bedridden. Furthermore, subjects do not need to undress which is especially practical in field studies.

The best prediction of body density was obtained using sex and BMI as independent variables $\left(R^{2} 0 \cdot 67\right.$, SEE $\left.0 \cdot 0100 \mathrm{~kg} / \mathrm{l}\right)$.

The SEE values, expressed as percentage body fat, of the models based on sex and two skinfolds, sex and four skinfolds, and sex and BMI were 5.6, 5.4 and 4.8\% respectively. These errors are comparable with reported SEE in the prediction of body fat in the literature, which range from $3 \cdot 5-5 \cdot 5 \%$ in old age groups.

Stature is known to decrease with age due to kyphosis and a shrinkage of the spinal vertebrae (Kuczmarski, 1989). This will affect BMI, and thus the prediction of body density from BMI. Shrinkage of the spinal vertebrae and kyphosis was of course already present in the present study population, thus this effect is already partly corrected for. To evaluate the effect of an underestimation of real stature by $0.05 \mathrm{~m}$, the difference in predicted density from BMI was calculated. An underestimation of stature by $0.05 \mathrm{~m}$ results in an overestimation of body fat content of only 1.9 (SD 0.3$) \%$ in women and $1.5(\mathrm{SD} 0.2) \%$ in men. Thus, quite a large error in the measurement of stature results only in small errors in predicted body density.

In all models age was not included. Dividing the total study population into subgroups of 5 year intervals revealed no statistically significant differences between predicted and estimated density in any of the age groups. Besides, in the models containing skinfolds, age was not correlated with the residual error. Thus, it seems that the relationship between body density and skinfolds is not dependent on age between 60 and 87 years. The residual error of model 3 was slightly but significantly correlated with age $(r-0.15, P=0.03)$. Age significantly contributed to this model which contains sex and BMI. However, including age as independent variable in this model increased the explained variance by only $1 \%$ and decreased the SEE by $0.0001 \mathrm{~kg} / \mathrm{l}$. Because of the minor decrease in prediction error and the fact that no difference between predicted and estimated body density was found in any of the 5-year age groups, age was left out of the equation.

The use of body circumferences for the prediction of body fatness in the elderly has 
frequently been suggested by several authors (Young et al. 1963; Chumlea et al. 1984; Minten et al. 1991). In the present study circumferences of mid-upper arm, waist, hip and thigh were also measured and related to body density (results not shown). In women the hip circumference $(r-0.56, P=0.0001)$, and in men the waist circumference $(r-0.58$, $P=0.0001)$ was best correlated with body density. Since there were significant interactions between all circumferences and sex, we investigated whether sex-specific equations containing circumferences were better at predicting body density compared with the models shown in Table 4 . The explained variance for the best model containing one or more circumferences was $36 \%$ in women (hip and waist circumference) and $28 \%$ in men (waist circumference). In the sex-specific models some circumferences contributed significantly to models which already contained the sum of two or four skinfolds. However, the SEE of these models, which ranged from 0.0098 to $0.0116 \mathrm{~kg} / \mathrm{l}$, were comparable with the SEE of the three models in Table 4, and thus did not really improve the prediction of body density. Durnin \& Womersley (1974) also reported that complex equations, including skinfolds and several limb circumferences, resulted in only minimal increases in accuracy compared with equations based on skinfolds only. It was concluded that prediction equations using circumferences (together with other anthropometric measures) have no advantages over equations using only skinfolds or BMI. Difficulties in the measurement of circumferences due to a reduced elasticity of the skin and the abdominal wall in elderly subjects may be responsible.

As a reference method in the present study, hydrodensitometry was used. Despite the fact that Siri's formula (Siri, 1961) is generally used to calculate body fat content in elderly subjects, it is questionable whether this is correct. With increasing age the density of the fatfree mass may decrease due to demineralization of the bone and changes in body water. Using a two-compartment model with the assumption that the density of the fat-free mass is $1.100 \mathrm{~kg} / \mathrm{l}$ could result in a systematic overestimation of body fat content in elderly subjects by $1-2 \%$ (Deurenberg et al. 1989 b). Moreover, with increasing fatness the relative amounts of minerals and protein in the fat-free mass may decrease (Deurenberg et al. $1989 a$ ). Therefore, in elderly people calculation of body fat content from body density needs some care. Baumgartner et al. (1991) investigated the difference in estimated body fat content of elderly men and women between a two- and a four-compartment model. The mean difference between the two methods was about $1.7 \%$, and was correlated with the aqueous fraction of the fat-free mass but not with age or with the mineral fraction of the fat-free mass. This suggests that the error in body fat made by using a two-compartment model depends predominantly on the hydration of the fat-free mass. Based on the calculations of Deurenberg et al. $(1989 a, b)$, adjustments can be made to Siri's formula. Therefore, body density, used as a dependent variable in the present study, can be used in the adjusted or unadjusted Siri's formula to calculate body fat content. It remains that at an individual level, even after any adjustment of Siri's formula, an error of about $3 \%$ body fat is possible using the hydrodensitometric method (Siri, 1956; Lohman, 1981).

The prediction formulas developed in the present study, based on BMI or the sum of two or four skinfolds, were internally cross validated and also externally validated in an independent sample. These procedures revealed that the formulas are valid for the estimation of body fat content in groups of elderly subjects. As with all prediction equations, one should always be cautious when applying the formula to elderly populations that are substantially different from the present study. Individual values should always be interpreted cautiously.

The authors would like to thank all participants for their enthusiastic participation in the study. We are indebted to Laura Voorrips and the students of the Department of Human 
Nutrition for performing the measurements. We thank Frans Schouten for his technical assistance and Dr W. H. M. Saris for providing the data for the validation sample.

\section{REFERENCES}

Baumgartner, R. N., Heymsfield, S. B., Lichtman, S., Wang, J. \& Pierson, R. N. (1991). Body composition in elderly people: effect of criterion estimates on predictive equations. American Journal of Clinical Nutrition $\mathbf{5 3}$, 1345-1353.

Blanchard, J., Conrad, K. A. \& Harrison, G. G. (1990). Comparison of methods for estimating body composition in young and elderly women. Journal of Gerontology 45, B119-B124.

Borkan, G. A. \& Norris, A. H. (1977). Fat redistribution and the changing body dimensions of the adult male. Human Biology 49, 495-514.

Carmelli, D., McElroy, M. R. \& Rosenman, R. H. (1991). Longitudinal changes in fat distribution in the Western Collaborative Group Study: a 23-year follow-up. International Journal of Obesity 15, 67-74.

Centraal Bureau voor de Statistiek (1992). Vademecum gezondheidsstatistiek Nederland 1992 (Vade-mecum health statistics, the Netherlands 1992). 's-Gravenhage: SDU/uitgeverij/CBS-publikaties.

Chumlea, W. C. \& Baumgartner, R. N. (1989). Status of anthropometry and body composition data in elderly subjects. American Journal of Clinical Nutrition 50, 1158-1166.

Chumlea, W. C., Baumgartner, R. N., Garry, P. J., Rhyne, R. L., Nicholson, C. \& Wayne, S. (1992). Fat distribution and blood lipids in a sample of healthy elderly people. International Journal of Obesity 16, 125-133.

Chumlea, W. C., Roche, A. F. \& Webb, P. (1984). Body size, subcutaneous fatness and total body fat in older adults. International Journal of Obesity $8,311-317$.

De Groot, L. C. P. G. M., Sette, S., Zajkás, G., Carbajal, A. \& Amorim Cruz, J. A. (1991). Nutritional status: anthropometry. Euronut SENECA investigators. European Journal of Clinical Nutrition 45, Suppl. 3, $31-42$.

Deurenberg, P., Leenen, R., van der Kooy, K. \& Hautvast, J. G. A. J. (1989a). In obese subjects the body fat percentage calculated with Siri's formula is an overestimation. European Journal of Clinical Nutrition 43, $569-575$.

Deurenberg, P., Weststrate, J. A. \& Seidell, J. C. (1991). Body mass index as a measure of body fatness: age- and sex-specific prediction formulas. British Journal of Nutrition 65, 105-114.

Deurenberg, P., Weststrate, J. A. \& van der Kooy, K. $(1989 \mathrm{~b})$. Is an adaptation of Siri's formula for the calculation of body fat percentage from body density in the elderly necessary? European Journal of Clinical Nutrition 43, 559-568.

Durnin, J. V. G. A. \& Womersley, J. (1974). Body fat assessed from total body density and its estimation from skinfold thickness: measurements on 481 men and women aged from 16 to 72 years. British Journal of Nutrition 32, 77-97.

Garrow, J. S. \& Webster, J. (1985). Quételet's index $\left(\mathrm{W} / \mathrm{H}^{2}\right)$ as a measure of fatness. International Journal of Obesity 9, 147-153.

Heitmann, B. L. (1990). Evaluation of body fat estimated from body mass index, skinfolds and impedance. A comparative study. European Journal of Clinical Nutrition 44, 831-837.

Johansson, A. G., Forslund, A., Sjödin, A., Mallmin, H., Hambraeus, L. \& Ljunghall, S. (1993). Determination of body composition - a comparison of dual-energy x-ray absorptiometry and hydrodensitometry. American Journal of Clinical Nutrition 57, 323-326.

Kaye, S. A., Folsom, A. R., Sprafka, J. M., Prineas, R. J.\& Wallace, R. B. (1991). Increased incidence of diabetes mellitus in relation to abdominal adiposity in older women. Journal of Clinical Epidemiology 44, 329-334.

Kubena, K. S., McIntosh, W. A., Georghiades, M. B. \& Landmann, W. A. (1991). Anthropometry and health in the elderly. Journal of the American Dietetic Association 91, 1402-1407.

Kuczmarski, R. J. (1989). Need for body composition information in elderly subjects. American Journal of Clinical Nutrition 50, $1150-1157$.

Lohman, T. G. (1981). Skinfolds and body density and their relation to body fatness: a review. Human Biology 53, $181-225$.

Löwik, M. R. H., Hofman, Z., Kok, F. J., Wedel, M., Hulshof, K. F. A. M., Odink, J. \& Schaafsma, G. (1991). Nutrition and blood pressure among elderly men and women (Dutch Nutrition Surveillance System). Journal of the American College of Nutrition 10, 149-155.

Mattila, K., Haavisto, M. \& Rajala, S. (1986). Body mass index and mortality in the elderly. British Medical Journal 292, 867-868.

Minten, V. K. A. M., Löwik, M. R. H., Deurenberg, P. \& Kok, F. J. (1991). Inconsistent associations among anthropometric measurements in elderly Dutch men and women. Journal of the American Dietetic Association 91, 1408-1412.

Noppa, H., Andersson, M., Bengtsson, C., Bruce, A. \& Isaksson, B. (1979). Body composition in middle-aged women with special reference to the correlation between body fat mass and anthropometric data. American Journal of Clinical Nutrition 32, 1388-1395.

Norgan, N. G. \& Ferro-Luzzi, A. (1982). Weight-height indices as estimators of fatness in men. Human Nutrition: Clinical Nutrition 36C, 363-372. 
Schwartz, R. S., Shuman, W. P., Bradbury, V. L., Cain, K. C., Fellingham, G. W., Beard, J. C., Kahn, S. E., Stratton, J. R., Cerqueira, M. D. \& Abrass, I. A. (1990). Body fat distribution in healthy young and older men. Journal of Gerontology 45, M181-M185.

Siri, W. E. (1956). The gross composition of the body. In Advances in Biological and Medical Physics, pp. 239-280. New York: Academic Press.

Siri, W. E. (1961). Body composition from fluid spaces and density: analysis of methods. In Techniques for Measuring Body Composition, pp. 223-244. Washington DC: National Academy of Sciences.

Svendsen, O. L., Haarbo, J., Heitman, B. L., Gotfredsen, A. \& Christiansen, C. (1991). Measurement of body fat in elderly subjects by dual-energy X-ray absorptiometry, bioelectrical impedance, and anthropometry. American Journal of Clinical Nutrition 53, 1117-1123.

Volkert, D., Kruse, W., Oster, P. \& Schlierf, G. (1992). Malnutrition in geriatric patients: diagnostic and prognostic significance of nutritional parameters. Annals of Nutrition and Metabolism 36, 97-112.

Womersley, J. \& Durnin, J. V. G. A. (1977). A comparison of the skinfold method with extent of 'overweight' and various weight-height relationships in the assessment of obesity. British Journal of Nutrition 38, $271-284$.

Young, C. M., Blondin, J., Tensuan, R. \& Fryer, J. H. (1963). Body composition of 'older' women. Journal of the American Dietetic Association 43, 344-348. 